\title{
Ozone Therapy in Patients with Burn Disease
}

\author{
Andrew K. Martusevich1, Sergey P. Peretyagin ${ }^{2}$, Mikhail V. Ruchin ${ }^{3}$, Andrew A. Struchkov ${ }^{1}$ \\ ${ }^{1}$ Privolzhsky Federal Medical Research Centre, Nizhny Novgorod, Russia; ${ }^{2}$ Association of Russian Ozone \\ Therapeutists, Nizhny Novgorod, Russia; ${ }^{3}$ Nizhny Novgorod State University Named after N.I. Lobachevsky, \\ Nizhny Novgorod, Russia
}

Correspondence to: Andrew K. Martusevich, cryst-mart@yandex.ru

Keywords: Burn, Therapy, Endotoxicosis, Detoxication, Ozone Therapy, Antioxidants

Received: January 28, $2018 \quad$ Accepted: February 25, $2018 \quad$ Published: February 28, 2018

Copyright $\odot 2018$ by authors and Scientific Research Publishing Inc.

This work is licensed under the Creative Commons Attribution International License (CC BY 4.0).

http://creativecommons.org/licenses/by/4.0/

\section{Open Access}

\section{ABSTRACT}

Objectives. Using of systemic ozone therapy connecting with antioxidants in early period of burn disease for detoxication and metabolic disorders correction is investigated. Materials and Methods. We used active preventive metabolic detoxication in early period of burn disease $\left(5^{\text {th }}-15^{\text {th }}\right.$ days after shock stage). It includes, besides complex infusion and transfusion therapy and classic pharmacological treatment, employment of antioxidants with succinic acid (reamberin, mexidol), systemic ozone therapy (intravenous injections of ozonated sodium chloride solution with ozone concentration $120-240 \mu \mathrm{g} / \mathrm{mL}$; saturating ozone concentration in gas flow-5000 $\mu \mathrm{g} / \mathrm{L}$, sparging speed $-2 \mathrm{l} / \mathrm{min}$ ), major autohemotherapy (twice a week; ozone dose-250 - $300 \mu \mathrm{g} / \mathrm{mL}$ ) and monitor cleansing of bowels with rectal ozone insufflations (ozone dose-1000 $\mu \mathrm{g} / \mathrm{mL}$ ). Estimation of personal oxidant dose and treatment effectiveness is carried out by biochemiluminescence control of pro- and antioxidant system state. Complex patient study also includes endotoxicosis markers (blood level of glucose, creatinine, bilirubin, urea and intermediate molecular weight peptides), proteolytic enzymes activity (tripsin, antitripsin, elastase), cardiovascular and microcirculation function examination (tetrapolar rheography, spirography, laser Doppler flowmetry) at burn disease dynamics. We formed two patients groups: first control group (20 burned patients) received a traditional therapy; second group (20 burned patients) got a described detoxication complex additional to treatment of first group. All patients had large burns (more than $20 \%$ body square). Indications for parenteral ozone therapy are signs of hypoxia (hypoxemia, elevated lactate level, depressed lactate dehydrogenase activity) and toxemia (increased blood level of glucose, creatinine, urea, intermediate molecular weight peptides, fibrine degradation products, lypoperoxidation intensification); cardiovascular dysfunction; respiratory function disorders. Results. Method of ozone dose individualization in intravenous ozone ther- 


\begin{abstract}
apy and pharmacological treatment as oxidation stress correction is shown. This method is based on biochemiluminescence detection of patient blood antioxidant system reaction in ozonization in vitro. It is important that first stage of method is pro- and antioxidant potential estimation. Conclusions. It was shown that this algorithm use determines fully correction of oxygen homeostasis disorders and endotoxicosis. It optimizes results of complex treatment of burned patients.
\end{abstract}

\title{
1. INTRODUCTION
}

Burn disease is one of the main pathogenic factors in systemic inflammatory response syndrome (SIRS) and multiorganic insufficiency formation is endotoxicosis. Main substrates of this pathological process are tissue toxins and non-fully oxidized, hypoxia-associated metabolites. Common chirurgical indication for efferential therapy is second or third degree of endotoxicosis [1-3], but this tactic is not usually adequate in burn disease.

We study oxygen active forms (ozone, hydrogen peroxide, singlet oxygen etc.) system using possibilities in urgent pathology, associated with hypoxia and toxemia, for oxygen homeostasis correction. Ozone therapy standard schemes, recommended by V. Bocci (1999), R. Vieban (2007), S. Menendes et al. (2008) and others specialists $[4,5]$, are not effective, because at this disease oxygen homeostasis disorders are connected with oxidative stress, pro- and antioxidant disbalance, proteolysis, lypolysis and multiorganic dysfunction $[3,6,7]$. It was shown early, that pro- and antioxidant balance is individual organism characteristic, determined by endogenic and exogenic factors summation $[3,8,9]$. In connection with it, treatment tactics choice may be individualized by lypoperoxidation and antioxidant potential state of each patient $[2,7]$. It is necessary to estimate the organism response on antioxidant or oxidation inductor injections (e.g. ozone). This thesis determines ozone use with obligatory individual monitoring of pro- and antioxidant system state.

So, the purpose of this study was the estimation of ozone therapy effectiveness in patients with burn disease.

\section{MATERIALS AND METHODS}

\subsection{Material and Groups Characteristics}

Our open, prospective study was performed from 2012 to 2016 in Burn Department of Privolzhsky Federal Medical Research Centre. We used active preventive metabolic detoxication in early period of burn disease $\left(5^{\text {th }}-15^{\text {th }}\right.$ days after shock stage). It includes, besides complex infusion and transfusion therapy and classic pharmacological treatment, employment of antioxidants with succinic acid (reamberin, mexidol), systemic ozone therapy (intravenous injections of ozonated sodium chloride solution with ozone concentration $120-240 \mu \mathrm{g} / \mathrm{mL}$; saturating ozone concentration in gas flow- $5000 \mu \mathrm{g} / \mathrm{L}$, sparging speed-2 1/min), large autohaemotherapy (twice a week; ozone dose-250 - $300 \mu \mathrm{g} / \mathrm{mL}$ ) and monitor cleansing of bowels with rectal ozone insufflations (ozone dose- $1000 \mu \mathrm{g} / \mathrm{mL}$ ).

Patients are including in our study had deep extensive burns (from 10 to 40 percents of body square; II degree on modern classification of burns deep). The criteria for exclusion were the age of patients (less than 18 and over 60 years), as well as the presence of severe comorbidities. We formed two patients groups: first control group (20 burned patients) received a traditional therapy, second group (20 burned patients) get a described detoxication complex additionally to treatment of first group. All patients had large burns (more than $20 \%$ body square).

\subsection{Methods}

Estimation of personal oxidant dose and treatment effectiveness is carry out by biochemilumines- 
cence control of pro- and antioxidant system state. Complex patient study also includes endotoxicosis markers (blood level of glucose, creatinine, bilirubin, urea and intermediate molecular weight peptides), proteolytic enzymes activity (tripsin, antitripsin, elastase), cardiovascular and microcirculation function examination (tetrapolar rheography, spirography, laser Doppler flowmetry [10]) at burn disease dynamics.

Indications for parenteral ozone therapy are signs of hypoxia (hypoxemia, elevated lactate level, depressed lactate dehydrogenase activity) and toxemia (increased blood level of glucose, creatinine, urea, intermediate molecular weight peptides, fibrine degradation products, lypoperoxidation intensification); cardiovascular dysfunction (hypokinetic type of hemodynamics, microcirculation reduction); respiratory function disorders.

Investigation was approved by Local Committee for Biomedical Ethics (LCBE) of Volga Federal Medical Research Center (Nizhny Novgorod). All patients are including in control and main groups signed informed consent to participate in the study.

\subsection{The Essence of Our Algorithm of Ozone Use}

We carried out therapy individualization test in several stages. Before parenteral ozone therapy or antioxidant treatment start we taken $20 \mathrm{ml}$ of patient blood (anticoagulant-heparin) for the estimation of initial oxidant potential of biological fluid. Intensity of lypoperoxidation and antioxidant system state was tested by induced biochemiluminescence $[2,7]$. Result of this test was indication for oxidant or antioxidant prescription. Next stage included evaluation of oxidation stress-inducing ozone dose in vitro. We fixed oxidation stress, if intensity of lypoperoxidation and reduction of antioxidant activity are registered. For this manipulation blood samples were divided on necessary number of aliquots, connected with number of tested ozone concentration. Ozonated sodium chloride solution with each ozone dose was added to each aliquot in special proportion $(\mathrm{NaCl}$ solution:blood $=0.1: 2)$. In control sample we added non-ozonated sodium chloride solution. Sample exposition time was $10 \mathrm{~min}$, after that it was centrifuged at $1250 \mathrm{~g}$ during $20 \mathrm{~min}$. In centrifuged blood plasma oxidation status was estimated by induced biochemiluminescence. Optimal ozone dose for intravenous ozone therapy is concentration which provoked temperate initiation of peroxidation with antioxidant system predominance.

At necessary of antioxidant prescription we selected ozone dose, which provoked oxidation stress. Its diagnostic criteria were described early. For this testing additional blood was divided on samples, which number are conform to investigated antioxidants number. After that oxidation-induced ozonated sodium chloride solution and tested antioxidants were added to blood samples (exposition time-10 min). After biochemiluminescence investigation we selected antioxidant with maximal activity.

\subsection{Statistical Analysis}

Statistical analysis of the data was performed with Statistica 6.0 program. Data were expressed as means \pm SE, the Student's t-test was used for detection of statistical difference.

\section{RESULTS AND DISCUSSION}

\section{Estimation of Method Effectiveness}

This technology of individual selection of oxidative and antioxidant therapy was introduced in work of burn center of Nizhny Novgorod Research Institute of Traumatology and Orthopaedics [2].

Analysis of controlled parameters demonstrated considerable metabolic disorders in patients' blood at complex treatment start. So, at early period of burn disease all patients had pathological changes of proand antioxidant systems state, characterizing by oxidation stress presence (elevation of lypoperoxidation level, accumulation of its primary, intermediate and terminal products with parallel reduction of antioxidant system activity). In addition, blood metabolic changes included hypoproteinemia, hypoalbuminemia and endotoxicosis markers elevation.

It was stated, that ozonated sodium chloride solution usage in complex treatment of burn disease improved correction of metabolic disorders. So, adequate ozone dose for parenteral injections caused physi- 
ological stimulation of antioxidant potential. In this connection, blood antioxidant activity at patients of main group was higher, that in control group (Figure 1). This positive dynamics of metabolic systems adaptive reorganization, associated with pro- and antioxidant potential normalization, was accompanied by reduction of endotoxicosis markers level.

Estimation of blood pro- and antioxidant potential at systemic ozone therapy allowed to show its possibilities for antioxidant reserves elevation (at 25\% - 28\% to initial level), but parenteral ozone use also caused prooxidant system initiation in burned patients (at $8 \%-12 \%$ to initial level; Figure 2). Investigation of lypoperoxidation intermediate products level was not quite informative (Figure 3). This dynamics of controlled parameters was most optimal. It connected with positive changes of other oxygen-depended processes in organism homeostasis. Dynamics of intermediate molecules in both group of patients corresponded to the fact that ozone therapy inclusion in complex treatment of burns caused to reduction of oxidation stress intensity in postburn period (Figure 4).

Special direction of this work is monitor cleansing of bowels (with rectal ozone insufflations) role in complex detoxication therapy of burned patients. Our investigation shown, that this variant of ozone use allowed to reduce creatinine level on $30 \%$, urea level on $26 \%$ and intermediate peptide molecules on $36 \%$.

It was shown by our investigation that blood trispin activity elevated at $260 \%$ to normal level at $3-5$ day after thermal trauma. Elastase activity increased at $1000 \%$ to normal level in early period of burn disease, and antitripsin activity was reduced in 4 times to normal level. The changes reproduced strongly pronounced disbalance of organism proteolytic system.

In patients of control group at 10 day after burn tripsin activity reduced in 1,5 times, elastase activity - in 1.6 times, and antitripsin activity elevated in 1.5 times. At major autohaemotherapy with ozone proteinases activity reduced clearly than at control group. It is important, that on 10 day after thermal trauma antitripsin activity was elevated in 5 times ( 1.5 times higher than normal level).

So, ozone using in burns management caused to proteolysis inhibitors level elevation, which means that this criteria may be utilized as high sensitive marker of parenteral ozone therapy effectiveness and safety.

Next stage of our complex study is estimation of system and central hemodynamic state in parenteral injections of ozonated solutions (Figure 5 and Figure 6). Own data indicated the positive effect of ozone

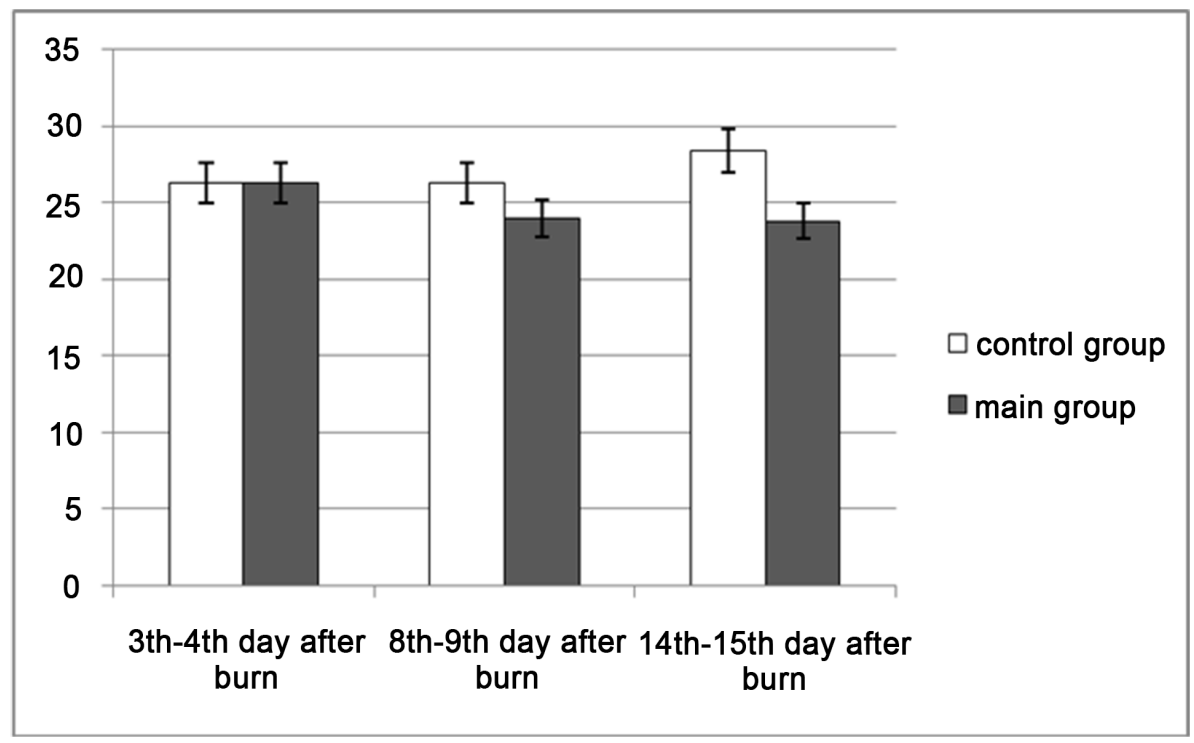

Figure 1. Blood lipid peroxidation level at control and main (ozone therapy addition) group patients ("*"- differences between the level of the parameter in the main and control groups are statistically significant, $\mathrm{p}<0.05)$. 


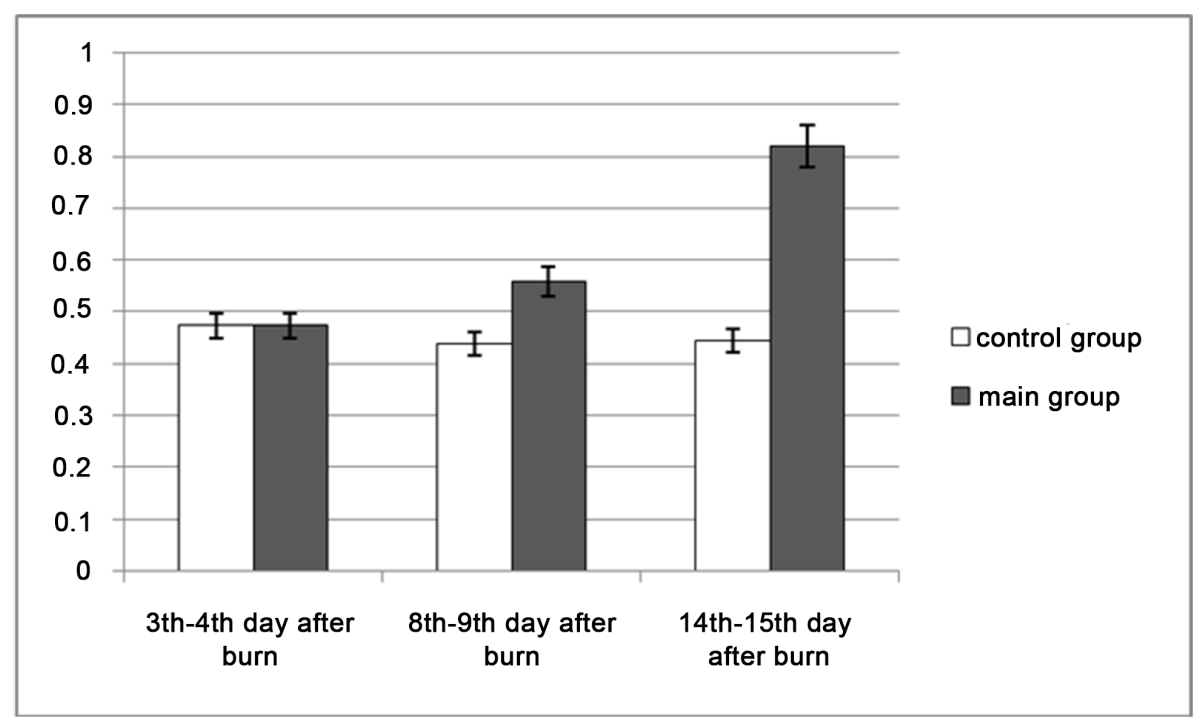

Figure 2. Blood antioxidant potential at control and main (ozone therapy addition) group patients ("*"-differences between the level of the parameter in the main and control groups are statistically significant, $p$ $<0.05)$.

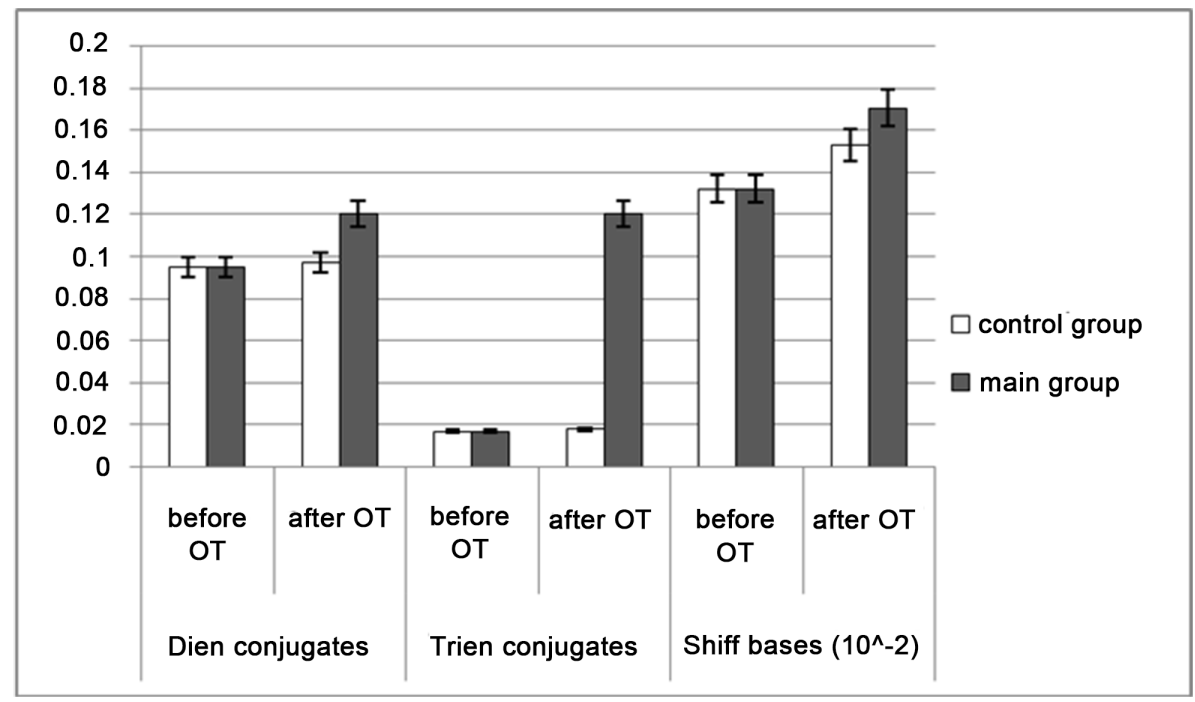

Figure 3. Blood lipid peroxidation intermediate products level in patient of control and main group (OT-ozone therapy; "*”-differences between the level of the parameter in the main and control groups are statistically significant, $\mathrm{p}<0.0$ ).

therapy on myocardium metabolic state and restoration of its function. Most informative criteria of this change are dynamics of heart rate and cardiac output. At systemic ozone use we fixed more clearly grown of cardiac output with less elevation of heart rate as against patients of control group (Figure 5).

Also, we analyzed dynamics of capillary blood flow at burn perifocal zone at systemic ozone therapy [10]. Tested skin regions (at $1 \mathrm{~cm}$ away from lip of a wound) were approved as main and non-wounded zone-as control. In this points level of microcirculation general parameter was estimated. Gradient between the points was calculated. 


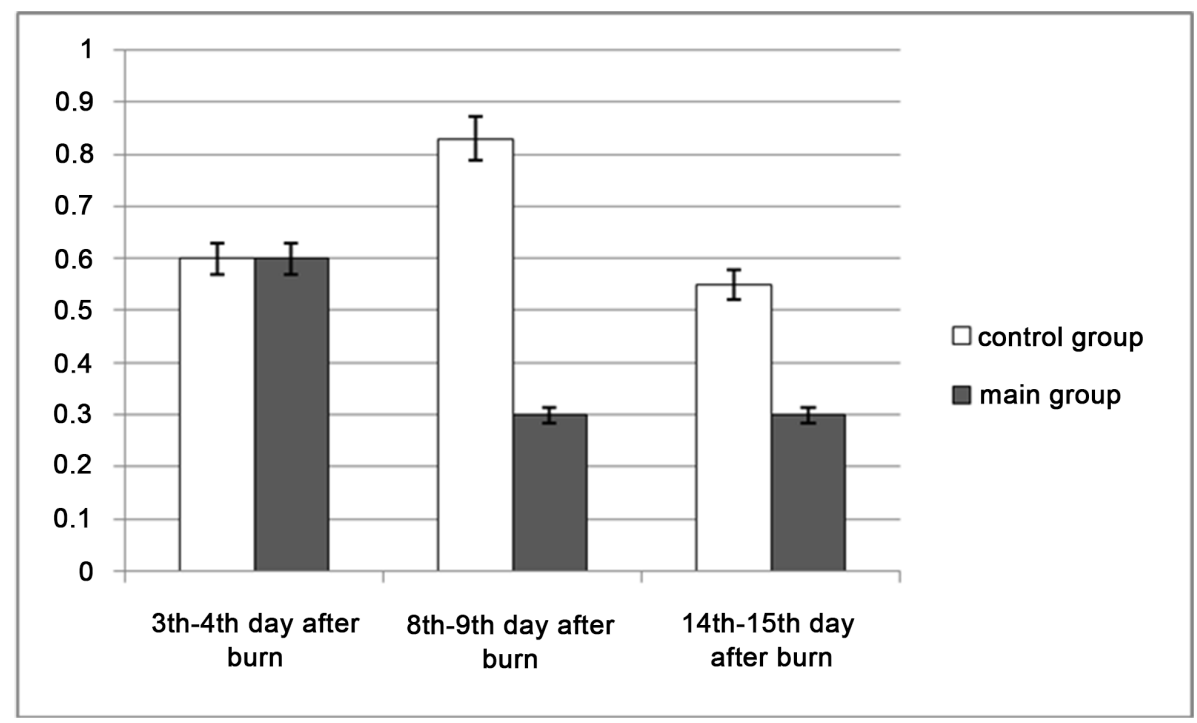

Figure 4. Blood level of intermediate peptide molecules (E254) at control and main groups ("*)-differences between the level of the parameter in the main and control groups are statistically significant, $p$ $<0.05)$.

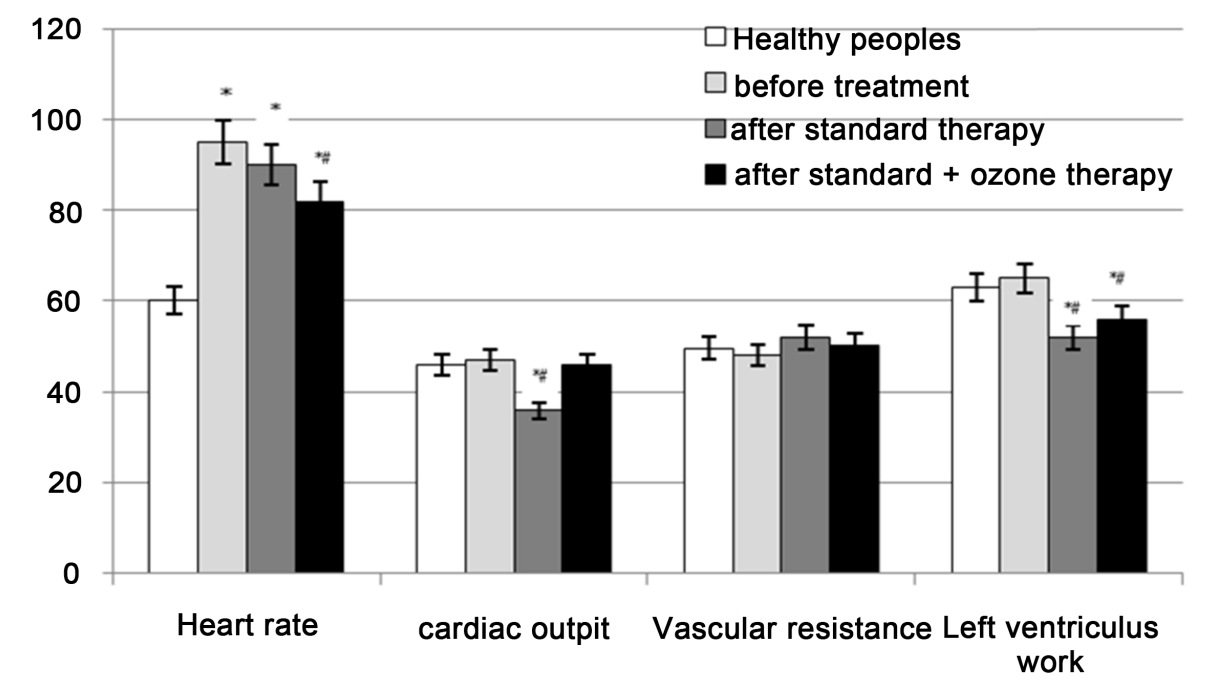

Figure 5. Central and peripheral hemodynamics parameters at traditional treatment of burn disease in connection with ozone therapy use ("*)-differences to parameter level before treatment are statistically significant, $\mathrm{p}<0.05$; “\#”- differences to healthy people are statistically significant, $\mathrm{p}<0.05)$.

Laser doppler flowmetry data demonstrate improvement of perifocal zone perfusion after systemic ozone therapy procedure (Table 1), which characterized by highest elevation of general microcirculation parameter in main region in comparison with control one. This tendency is determined by predominance of active regulatory mechanisms over passive.

In next period of early stage of burn disease level of general microcirculation parameter at control region had no differences, and at perifocal wound zone it increased constantly with tissue reperfusion. It can 


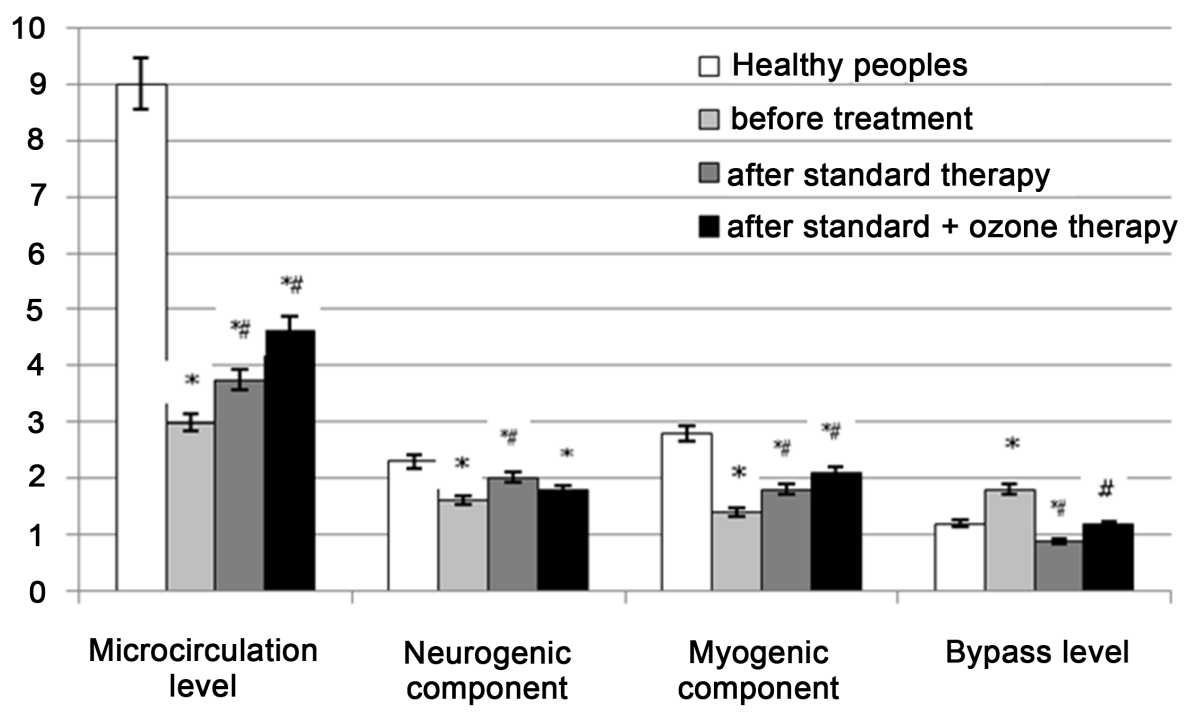

Figure 6. Dynamics of microcirculation state at traditional treatment of burn disease in connection with ozone therapy use ("*)-differences to parameter level before treatment are statistically significant, $\mathrm{p}<0.05$; "\#”- differences to healthy people are statistically significant, $\mathrm{p}<0.05$ ).

Table 1. Microcirculatory general parameter level at systemic ozone therapy dynamics.

\begin{tabular}{cccccc}
\hline & Initial state & $\begin{array}{c}1 \text { day after } \\
\text { trauma and } \\
\text { ozone use }\end{array}$ & $\begin{array}{c}3 \text { day after } \\
\text { trauma and } \\
\text { ozone use }\end{array}$ & $\begin{array}{c}5-7 \text { days after } \\
\text { trauma and } \\
\text { ozone use }\end{array}$ & $\begin{array}{c}12-14 \text { days } \\
\text { after trauma } \\
\text { and ozone use }\end{array}$ \\
\hline Main regions & $26.53 \pm 2.38$ & $32.52 \pm 1.38$ & $34.25 \pm 3.18$ & $38.42 \pm 2.23$ & $44.98 \pm 3.28$ \\
Control regions & $\begin{array}{c}38.95 \pm 2.4 \\
(\mathrm{p}>0.05)\end{array}$ & $\begin{array}{c}41.21 \pm 3.38 \\
(\mathrm{p}<0.05)\end{array}$ & $\begin{array}{c}40.95 \pm 2.16 \\
(\mathrm{p}<0.05)\end{array}$ & $39.52 \pm 2.21$ & $42.23 \pm 3.24$ \\
\hline
\end{tabular}

be connected with modulation of synthesis and/or release of biologically active substances, regulating microcirculation state at systemic ozone therapy. Tissue blood flow optimization correlated with reparation stimulation, epithelization and skin restoration. On our opinion, this microcirculation changes take place in organism at all, that is very important for adaptation ensuring at burn disease.

Additional evidence of positive action of systemic ozone therapy on organism homeostasis at burns was dynamics of proteom restoration. So, blood protein profile normalization was more effectively at patients, getting parenteral injections of ozonated sodium chloride solutions.

In addition, most patients of main group feel better, had a good appetite, optimization of efficiency, temperature level, reduced pain after parenteral ozone therapy course. So, we got a positive clinical effect of different ozone therapy method use in complex treatment of patients with burn disease. Also, this technology is economically grounded, because it allowed reduce total treatment cost.

Finally, we did not fixed any complications during and after used course of systemic ozone therapy in all patients of main group.

\section{DISCUSSION}

In Russia and all around the world ozone is primary used in wound treatment as an antibacterial agent $[1,6,11,12]$. Its high oxidative potential is causing hyperactivation of lipid peroxidation initiates the 
destructive processes in the cell walls of wound bacterial pathogens $[1,8,11]$. For this task solution high ozone are necessary.

Now there are a two ways of local ozone therapy of different wound. First method includes wound processing with gaseous ozone-oxygen mixtures [11-13]. Second technology is based on wound irrigation with ozonized saline or distilled water $[1,14,15]$. It was stated that antiseptic action of ozone is not only associated with its oxidative properties, but with different bioregulatory effects $[6,8,9]$, including optimization of oxidative metabolism [8], stimulating of growth factors [16] activity etc.

For both indicated methods clinical efficiency was demonstrated, but possibilities of systemic ozone therapy, such as intravenous infusions of ozonized saline, is poorly studied. This medical technology is used in Russia for treatment of different pathology (for example, in cardiology, gastroenterology and others $[4-6,9,17])$ not fully investigated for wound and burns management. That is why we have examined the effects of systemic ozone therapy in patients with extensive burns. It is established that the use of low doses of ozone $(1000-3000 \mu \mathrm{g} / \mathrm{mL})$ for intravenous infusions of ozonized saline (in conjunction with their individual selection) allows adjusting the systemic manifestations of burn disease. This provides more rapid relief of laboratory signs of intoxication and advanced rehabilitation patients.

As is generally known, «oligopeptides-inhibitors» system balance has a rank high among pathogenic factors of burn toxemia [2]. One of the most important component of this system is proteolysis, including multienzyme complex (tripsin, elastase etc.), determined organism adaptation. Tripsin is a key enzyme, which started digestive process, degradation of anomaly and mutated proteins [8]. Elastase is one of the most degradated enzymes of human organism, which destructed elastin and collagen fibres, blood plasma proteins, immunoglobulines, fibrinogen, hormones and others [8]. There is a large proteolysis inhibitors pool for proteinases activity protection. Most important component of this system is antitripsin, provided with $80 \%$ blood antiprotease protection.

\section{CONCLUSION}

Our data demonstrate the necessary of inclusion of ozone therapy in complex algorithm of burned patient management, because this method can modify the mechanisms of endogenic detoxication. It is very important to use individualization in oxidative therapy prescription, that is possible, if initial pro- and antioxidant system state is known. On this base, we can select adequate exogenic regulators of its disorders to optimization of oxygen-depend processes in organism of burned patients.

In our opinion, usage of suggested method of ozone and antioxidant dose selection may be important for individualization oxidative and antioxidant therapy in modern combustiology.

\section{REFERENCES}

1. Frascino, A.V., Mantesso, A., Corrêa, L. and Deboni, M.C. (2013) Aqueous-Ozone Irrigation of Bone Monocortical Wounds in Hyperglycemic Rats. Acta Cirúrgica Brasileira, 28, 327-333.

https://doi.org/10.1590/S0102-86502013000500002

2. Kuzmina, E.I., Peretyagin, S.P., Evstigneev, S.V., et al. (2000) Estimation of Antioxidant Potential in Blood Plasma of Burned Patients. NNIITO, Nizhny Novgorod.

3. Maslennikov, O.V. and Kontorschikova, K.N. (2008) Ozone Therapy. Nizhny Novgorod State Medical Academy, Nizhny Novgorod.

4. Rilling, Z. and Viebahn, R. (1997) Practice of Ozone-Oxygen Therapy. Hang, New York.

5. Vieban, R. (2009) Ozon-Sauerstoff-Therapie. MVS Medizinverlage, Stuttgart.

6. Alyekhina, S.P. and Scherbatyuk, T.G. (2003) Ozone Therapy. Clinical and Experimental Aspects. Litera, Nizhny Novgorod.

7. Kontorschikova, K.N., Peretyagin, S.P. and Kuzmina, E.I. (1989) Method of Chemical Substances Antioxidant 
Activity Estimation. SU Patent No. 1513405.

8. Zhuravlev, A.I. and Zubkova, S.M. (2014) Antioxidants. Free-Radical Pathology, Aging. Belye Alvy, Moscow.

9. Zmyzgova, A.V. and Maximov, B.A. (2003) Clinical Aspects of Ozone Therapy. NPC Ozonoterarii, Moscow.

10. Krupatkin, A.I. and Sidorov, V.V. (2005) Laser Doppler Flowmetry of Blood Microcirculation. Meditsina, Moscow.

11. Batinjan, G., Filipovic Zore, I., Vuletic, M. and Rupic, I. (2014) The Use of Ozone in the Prevention of Osteoradionecrosis of the Jaw. Saudi Medical Journal, 35, 1260-1263.

12. Shah, P., Shyam, A.K. and Shah, S. (2011) Adjuvant Combined Ozone Therapy for Extensive Wound over Tibia. Indian Journal of Orthopaedics, 45, 376-379. https://doi.org/10.4103/0019-5413.80332

13. Wainstein, J., Feldbrin, Z., Boaz, M. and Harman-Boehm, I. (2011) Efficacy of Ozone-Oxygen Therapy for the Treatment of Diabetic Foot Ulcers. Diabetes Technology \& Therapeutics, 13, 1255-1260. https://doi.org/10.1089/dia.2011.0018

14. Erginel, B., Erginel, T., Aksoy, B. and Dokucu, A.I. (2014) Effect of Ozone Therapy on Healing of Colonic Anastomosis in a Rat Model of Peritonitis. Balkan Medical Journal, 31, 249-253. https://doi.org/10.5152/balkanmedj.2014.13215

15. Gulmen, S., Kurtoglu, T., Meteoglu, I., et al. (2013) Ozone Therapy as an Adjunct to Vancomycin Enhances Bacterial Elimination in Methicillin Resistant Staphylococcus aureus Mediastinitis. Journal of Surgical Research, 185, 64-69. https://doi.org/10.1016/j.jss.2013.05.085

16. Wang, B., Dong, G.Z., Ju, Y.X. and Yan, C.S. (2014) Case-Control Study on Therapeutic Effects of Ozone and Triamcinolone Acetonide on the Treatment of Meniscal Injury. Zhongguo Gu Shang, 27, 295-298.

17. Zhang, J., Guan, M., Xie, C., et al. (2014) Increased Growth Factors Play a Role in Wound Healing Promoted by Noninvasive Oxygen-Ozone Therapy in Diabetic Patients with Foot Ulcers. Oxidative Medicine and Cellular Longevity, 2014, Article ID: 273475. https://doi.org/10.1155/2014/273475 